\title{
Transparent and Flexible Capacitors with an Ultrathin Structure by Using Graphene as Bottom Electrodes
}

\author{
Tao Guo ${ }^{1}$, Guozhen Zhang ${ }^{1}$, Xi Su ${ }^{1}$, Heng Zhang ${ }^{1}$, Jiaxian Wan ${ }^{1}$, Xue Chen ${ }^{1}$, Hao $\mathrm{Wu}^{2, *}$ \\ and Chang Liu ${ }^{1, *}$ \\ 1 Key Laboratory of Artificial Micro- and Nano-Structures of Ministry of Education, and School of Physics \\ and Technology, Wuhan University, Wuhan 430072, China; tao.g@whu.edu.cn (T.G.); \\ guozhen.zhang@whu.edu.cn (G.Z.); xsu@whu.edu.cn (X.S.); zhheng@whu.edu.cn (H.Z.); \\ j.x.wan@whu.edu.cn (J.W.); xuechen@whu.edu.cn (X.C.) \\ 2 Hubei Nuclear Solid Physics Key Laboratory, and School of Physics and Technology, Wuhan University, \\ Wuhan 430072, China \\ * Correspondence: h.wu@whu.edu.cn (H.W.); chang.liu@whu.edu.cn (C.L.)
}

Received: 27 October 2017; Accepted: 24 November 2017; Published: 28 November 2017

\begin{abstract}
Ultrathin, transparent and flexible capacitors using graphene as the bottom electrodes were directly fabricated on polyethylene naphthalate (PEN) substrates. $\mathrm{ZrO}_{2}$ dielectric films were deposited on the treated surface of graphene by atomic layer deposition (ALD). The deposition process did not introduce any detectible defects in the graphene, as indicated by Raman measurements, guaranteeing the electrical performances of the graphene electrodes. The Aluminum-doped zinc oxide (AZO) films were prepared as the top electrodes using the ALD technique. The capacitors presented a high capacitance density $\left(10.3 \mathrm{fF} / \mu \mathrm{m}^{2}\right.$ at $\left.10 \mathrm{kHz}\right)$ and a relatively low leakage current $\left(5.3 \times 10^{-6} \mathrm{~A} / \mathrm{cm}^{2}\right.$ at $1 \mathrm{~V}$ ). Bending tests revealed that the capacitors were able to work normally at an outward bending radius of $10 \mathrm{~mm}$ without any deterioration of electrical properties. The capacitors exhibited an average optical transmittance of close to $70 \%$ at visible wavelengths. Thus, it opens the door to practical applications in transparent integrated circuits.
\end{abstract}

Keywords: transparent and flexible capacitors; graphene; $\mathrm{ZrO}_{2}$ films; atomic layer deposition

\section{Introduction}

In recent years, transparent and flexible flat-panel displays formed on plastic substrates have attracted substantial attention, particularly in the field of wearable electronics, owing to their fascinating advantages, which include high optical transparency, good bendability, their light weight and their low cost $[1,2]$. In the pixel-drive circuit of displays, capacitors usually play the role of charging and discharging at very high speed [3,4]. A high capacitance is needed to ensure the color brightness of each pixel, while a low leakage current means a prolonged charge storage time when the pixel is in the off state [5]. Apart from this, bendability and transparency should also be seriously considered when the capacitors are applied in flexible electronics.

To achieve an excellent transparency and flexibility of the capacitors, the selection of high-performance electrode materials is crucial. Compared to ordinary transparent conducting films, graphene has superior performances in transmittance, conductivity and mechanical strength, owing to its thickness of one carbon atom [6,7]. As is well known, the tensile or compressive stress on the film surface is proportional to the film thickness. Along this line, the entire capacitor structure can be made ultrathin when graphene is used as the electrode, which facilitates substantial improvements in flexibility. Furthermore, a single layer of graphene has a very high transmittance of $97.7 \%$ in the visible region, which ensures the high transparency of the capacitors [8]. At present, commercial large-area graphene can be conveniently prepared by chemical vapor deposition (CVD) and transferred onto 
various target substrates. The lowest reported sheet resistance $(\sim 125 \Omega / \square)$ of the CVD-graphene is comparable to that of industrialized indium-tin oxide (ITO) electrodes $(\sim 100 \Omega / \square)[8,9]$. Thus, graphene is very suitable for fabricating transparent and flexible capacitors.

Capacitors with high capacitance, small featured size and low power consumption can be realized by employing high-k materials with wide bandgaps as dielectrics. Many high-k materials, including $\mathrm{Al}_{2} \mathrm{O}_{3}$ [10], $\mathrm{TiO}_{2}$ [11], $\mathrm{HfO}_{2}$ [12], $\mathrm{ZrO}_{2}$ [13], have been thoroughly investigated in the last few years. Among them, $\mathrm{ZrO}_{2}$ demonstrated great potential due to its high relative permittivity of about 25, and its relatively large bandgap of about $5.6 \mathrm{eV}$ [14]. In addition, its excellent temperature stability and low permeation rates for ambient gases are attractive in the sense that they can improve device reliability [15]. In our recent work, capacitors using $\mathrm{ZrO}_{2}$ film as the dielectric layer showed an ultralow leakage current while achieving a high capacitance density [16].

In order to fabricate graphene-based electronics, high-quality dielectric films on the top of the graphene are required as electrostatic gate dielectrics or tunnel barriers $[17,18]$. For the purpose of providing accurate control over the thickness of dielectric films, dielectric layers should be made in nanoscale and be of uniform coverage on the graphene, without pinholes. Fortunately, atomic layer deposition (ALD) is a powerful method for preparing high-quality dielectric films. It adopts an inherent self-limiting growth mode to realize the ALD process and demonstrates many advantages, such as accurate thickness control, high uniformity over a large area, and low defect density [19]. Although the preparation of $\mathrm{Al}_{2} \mathrm{O}_{3}$ and $\mathrm{HfO}_{2}$ on graphene has been studied [20-23], the reports referring to ALD-grown $\mathrm{ZrO}_{2}$ dielectric films are quite few.

In this work, ultrathin, transparent and flexible capacitors using graphene for the bottom electrodes were fabricated directly on polyethylene naphthalate (PEN) substrates. A two-step ALD process at temperatures of 100 and $150{ }^{\circ} \mathrm{C}$ was developed to gain high-quality $\mathrm{ZrO}_{2}$ films. Al doped $\mathrm{ZnO}$ (AZO) films were then deposited in-situ on the $\mathrm{ZrO}_{2}$ surface as the top electrodes. The capacitors had a total thickness of under $165 \mathrm{~nm}$, and presented a high capacitance density with a low leakage current. Bending tests indicated that the capacitors can work at an outward bending radius of $10 \mathrm{~mm}$ without any deterioration of the performance.

\section{Results and Discussion}

The surface of graphene is $\mathrm{sp}^{2}$-hybridized and lacks dangling bonds, which are necessary for chemical reactions during the initial nucleation of the ALD process. Generally, it is hard to grow high-quality dielectric films on the top of graphene. To solve this problem, functionalization of the graphene surface is performed to meet the demand of nucleation sites. So far, researchers have developed various surface-modification methods, which can be divided into chemical and physical methods [24-26]. However, these methods may damage the graphene, and inevitably introduce defects into the graphene. To overcome the drawbacks, Zheng et al. [27] recently reported enhanced nucleation of $\mathrm{Al}_{2} \mathrm{O}_{3}$ using adsorption of $\mathrm{H}_{2} \mathrm{O}$ on the graphene surface. In this way, a low leakage current was obtained by a two-step process at temperatures of 100 and $200{ }^{\circ} \mathrm{C}$. Practical application for photoelectric devices, however, was not mentioned.

The surface of graphene is chemically inert and lacks dangling bonds, yet $\mathrm{H}_{2} \mathrm{O}$ molecules can be physically absorbed by the van der Waals forces. Absorbed $\mathrm{H}_{2} \mathrm{O}$ molecules could act as nucleation sites, and their consistency would play an important role in the growth of the $\mathrm{ZrO}_{2}$ seed layers. The final state of water mainly depends on the chamber temperature and the $\mathrm{H}_{2} \mathrm{O}$ dosage. The essence of $\mathrm{H}_{2} \mathrm{O}$ physical adsorption is related to water vapor liquefying on the surface of graphene. This happens easily when the temperature of the $\mathrm{H}_{2} \mathrm{O}$ vapor reaches its liquefaction point $[27,28]$. Thus, the initial temperature of the ALD chamber was set at $100{ }^{\circ} \mathrm{C}$ to ensure $\mathrm{H}_{2} \mathrm{O}$ molecules were able to continuously adhere to the graphene by gas-solid physical absorption. $\mathrm{H}_{2} \mathrm{O}$ dosage can be controlled by the pulse time of liquid water. Prior to the deposition of the $\mathrm{ZrO}_{2}$ dielectric films, liquid water was introduced into the ALD chamber by the carrier gas $\mathrm{N}_{2}$. The liquid water pulse time and the interval between two pulses were set at the same period, $10 \mathrm{~s}$, which gave enough time for the $\mathrm{H}_{2} \mathrm{O}$ molecules to be 
transformed between the two phases (liquid and gas) and absorbed onto the graphene. In order to find out the optimum $\mathrm{H}_{2} \mathrm{O}$ treatment conditions, and to obtain continuous nucleation sites for the $\mathrm{ZrO}_{2}$ seed layers, 1 to 6 cycles of $\mathrm{H}_{2} \mathrm{O}$ treatment were tested. After that, $5 \mathrm{~nm}$ thick $\mathrm{ZrO}_{2}$ seed layers were grown at $100{ }^{\circ} \mathrm{C}$ with $42 \mathrm{ALD}$ cycles.

Figure 1 presents the results of atomic force microscope (AFM) measurements. The surface morphologies of the $\mathrm{ZrO}_{2}$ seed layers on graphene with $\mathrm{H}_{2} \mathrm{O}$ treatment for $0-6$ cycles are shown in Figure $1 \mathrm{a}-\mathrm{g}$, respectively. From Figure $1 \mathrm{a}, \mathrm{b}$, one can see that many pinholes exist in the $\mathrm{ZrO}_{2}$ film with $\mathrm{H}_{2} \mathrm{O}$ treatment for 0 and 1 cycle. When increasing the number of $\mathrm{H}_{2} \mathrm{O}$ treatment cycles, the pinholes reduced obviously, and the $\mathrm{ZrO}_{2}$ films became denser, as seen in Figure 1c,d. For $\mathrm{H}_{2} \mathrm{O}$ treatment for 3 cycles, the pinholes could hardly be seen in the seed layer. However, when number of $\mathrm{H}_{2} \mathrm{O}$ treatment cycles reached 4, the pinholes recurred, as can be seen in Figure 1e. Furthermore, their density increased with increasing $\mathrm{H}_{2} \mathrm{O}$ treatment cycles, as seen in Figure 1f,g. Meanwhile, the root-mean-square (RMS) roughness of the $\mathrm{ZrO}_{2}$ seed layers was minimized after $\mathrm{H}_{2} \mathrm{O}$ treatment for 3 cycles, as seen in Figure $1 \mathrm{~h}$. Fewer $\mathrm{H}_{2} \mathrm{O}$ treatment cycles $(<3)$ led to insufficient nucleation sites, causing a relatively rough surface. However, when it was over-treated by $\mathrm{H}_{2} \mathrm{O}$ (treatment cycles $\geq 4$ ), lots of clusters were formed on the graphene surface due to the van der Waals force between $\mathrm{H}_{2} \mathrm{O}$ molecules, and the graphene was unable to overcome the inter-molecular attraction and surface tension of the $\mathrm{H}_{2} \mathrm{O}$ molecules, resulting in a substantial increase in the surface roughness, and poor morphology in the subsequent ALD-grown $\mathrm{ZrO}_{2}$ seed layers. Thus, the optimum number of cycles of $\mathrm{H}_{2} \mathrm{O}$ treatment was determined to be 3 cycles. $5 \mathrm{~nm}$ thick $\mathrm{ZrO}_{2}$ seed layers were then grown under this optimum condition at $100{ }^{\circ} \mathrm{C}$. Subsequently, higher-quality $\mathrm{ZrO}_{2}$ dielectric films were grown at $150{ }^{\circ} \mathrm{C}$.


Figure 1. AFM images of $\mathrm{ZrO}_{2}$ seed layers on graphene with different cycles of $\mathrm{H}_{2} \mathrm{O}$ treatment at $100{ }^{\circ} \mathrm{C}$ : (a) 0; (b) 1; (c) 2; (d) 3; (e) 4; (f) 5; and (g) 6 cycles; (h) The RMS roughness of the $\mathrm{ZrO}_{2}$ surface. 
High-quality graphene is crucial for electronic applications. Raman spectroscopy measurements were used to qualitatively evaluate whether the $\mathrm{H}_{2} \mathrm{O}$ treatment and subsequent ALD-growth of the $\mathrm{ZrO}_{2}$ films introduced significant defects, or even deteriorated the structural and electrical properties of graphene. Figure 2a shows three typical Raman peaks (D, G, 2D) of the pristine graphene and graphene covered by the $\mathrm{ZrO}_{2}$ films with and without the surface treatment [29]. Pristine graphene presents distinct $G$ and $2 D$ peaks at $\sim 1600$ and $\sim 2700 \mathrm{~cm}^{-1}$, respectively. The D peak could be observed in the pristine graphene at $1350 \mathrm{~cm}^{-1}$, which was related to the defects in graphene, and indicated that the defects of the CVD-grown pristine graphene could not be ignored [30]. The ratio of the peak intensities between $\mathrm{D}$ and $\mathrm{G}\left(\mathrm{I}_{\mathrm{D}} / \mathrm{I}_{\mathrm{G}}\right)$ clearly reflected the defect density of graphene [31]. Figure $2 \mathrm{~b}$ shows the $\mathrm{I}_{\mathrm{D}} / \mathrm{I}_{\mathrm{G}}$ ratios, which were almost unchanged with and without surface treatment compared to that of the pristine graphene, implying that the process of surface treatment and subsequent ALD growth of the $\mathrm{ZrO}_{2}$ films at $100{ }^{\circ} \mathrm{C}$ did not introduce noticeable defects into the graphene. As a consequence, no significant defects were generated in the graphene, not only in the process of $\mathrm{H}_{2} \mathrm{O}$ treatment, but also in the process of ALD growth of the $\mathrm{ZrO}_{2}$ films.
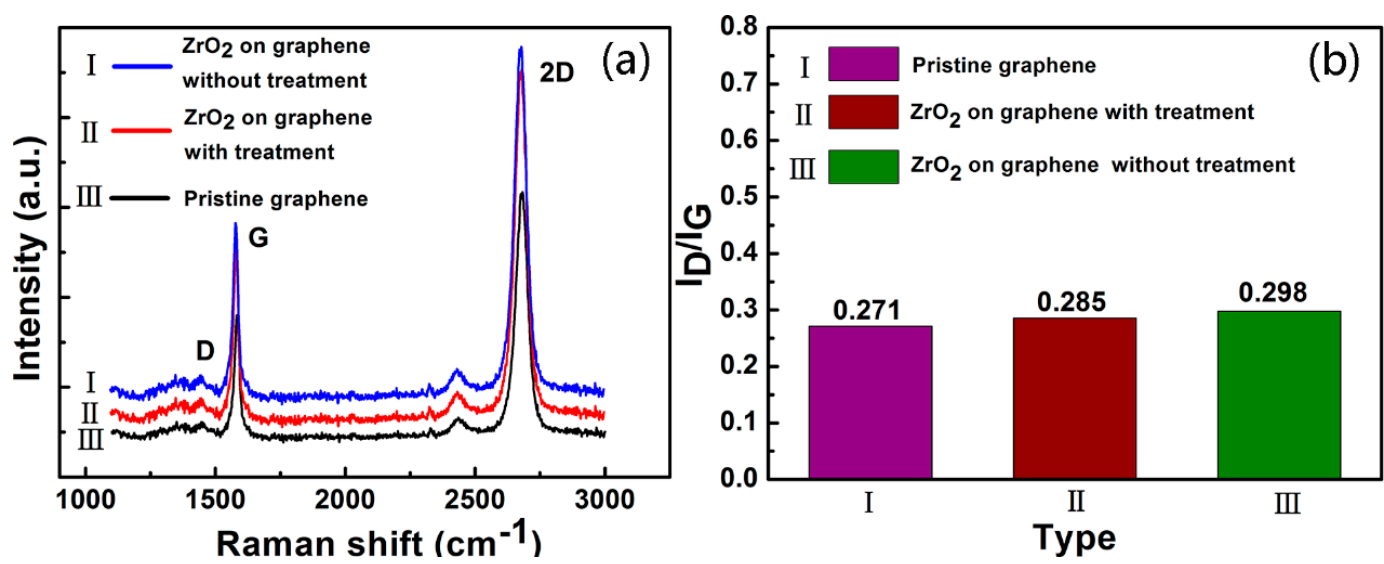

Figure 2. (a) Raman spectra and (b) the ratio of $\mathrm{I}_{\mathrm{D}} / \mathrm{I}_{\mathrm{G}}$ of pristine graphene and graphene covered with $5 \mathrm{~nm}$ thick $\mathrm{ZrO}_{2}$ films with and without surface treatment.

Figure 3a shows the schematic diagram of the capacitors fabricated on quartz substrates. $\mathrm{I}-\mathrm{V}$ curves were measured to analyze the dependence of the leakage current on the thickness of the dielectric layers prepared at $150{ }^{\circ} \mathrm{C}$ with and without the surface treatment, as shown in Figure $3 \mathrm{~b}$. It should be noted that the leakage current of the capacitors was very high without the surface treatment when the thickness of the $\mathrm{ZrO}_{2}$ dielectric films was $10 \mathrm{~nm}$. In contrast, the leakage current decreased to $5.3 \times 10^{-6} \mathrm{~A} / \mathrm{cm}^{2}$ after the surface treatment. However, when the thickness of $\mathrm{ZrO}_{2}$ dielectric films was increased to 15 and $20 \mathrm{~nm}$, the leakage currents decreased to $3.6 \times 10^{-7}(15 \mathrm{~nm})$ and even $4.5 \times 10^{-8}(20 \mathrm{~nm}) \mathrm{A} / \mathrm{cm}^{2}$ at $1 \mathrm{~V}$, indicating that nano-capacitors with low leakage currents can be prepared on graphene whose surface has been physically treated by $\mathrm{H}_{2} \mathrm{O}$ adsorption. To balance the leakage current and capacitance of the capacitors, the thickness of the $\mathrm{ZrO}_{2}$ dielectric films was finally fixed at $10 \mathrm{~nm}$ in this study.

As shown in Figure $3 \mathrm{c}$, the capacitance density reached $10.3 \mathrm{fF} / \mu \mathrm{m}^{2}$ at $10 \mathrm{kHz}$, which corresponds to a dielectric constant of 11.6. The capacitance density declined slightly when the voltage was swept from -0.5 to $0.5 \mathrm{~V}$. A possible reason relates to the residuals of the incomplete chemical reaction between TDMAZ and $\mathrm{H}_{2} \mathrm{O}$ at the relatively low temperatures of 100 and $150{ }^{\circ} \mathrm{C}$, which formed $\mathrm{ZrO}_{2}$ films that contained impurities. When the $\mathrm{ZrO}_{2}$ films were grown at $200{ }^{\circ} \mathrm{C}$, the chemical reaction was more sufficient, and the capacitance remained almost unchanged in a voltage range from -2 to $2 \mathrm{~V}$, as seen before in our previous work [32]. In this study, however, we used the PEN substrates to prepare flexible capacitors that cannot bear heating at $200{ }^{\circ} \mathrm{C}$. Figure $3 \mathrm{~d}$ presents a comparison of the capacitance density between those with and without the surface treatment by $\mathrm{H}_{2} \mathrm{O}$. The former remained nearly 
unchanged throughout the frequency range from 1 to $100 \mathrm{kHz}$, and declined significantly at frequencies above $100 \mathrm{kHz}$. The dielectric loss occurring at high frequencies originated mainly from the relatively high sheet resistance of the graphene $(\sim 500 \Omega / \square)$ and AZO $(\sim 400 \Omega / \square)$ electrodes. The latter had pretty smaller capacitance densities, which dropped slightly when the frequency was above $10 \mathrm{kHz}$, but dropped heavily above $100 \mathrm{kHz}$. Thus, it can be concluded that the capacitors can work steadily at frequencies between 1 and $100 \mathrm{kHz}$ with $\mathrm{H}_{2} \mathrm{O}$ treatment of the graphene.
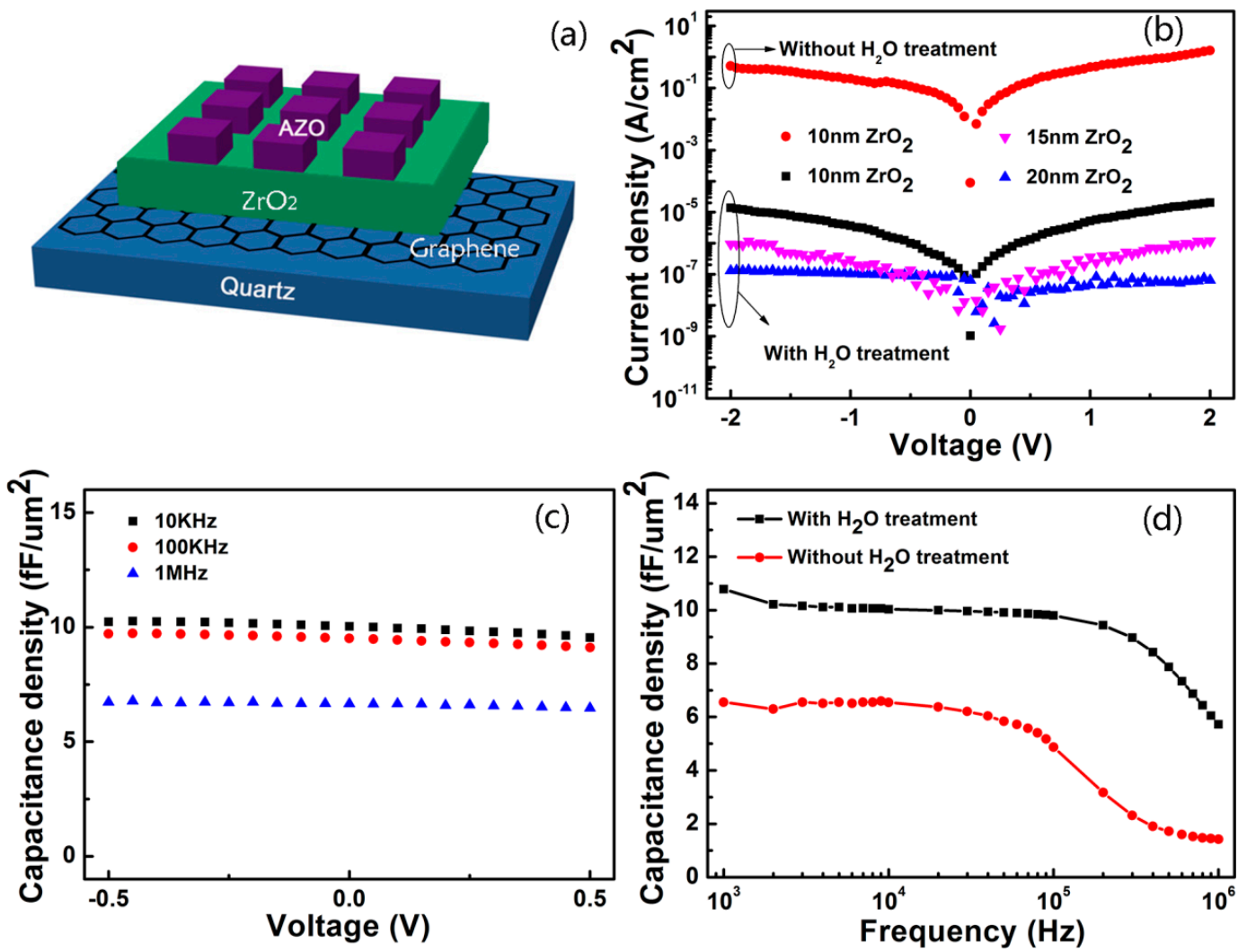

Figure 3. (a) A schematic diagram of the capacitors on quartz substrates; the electrical characteristics of the capacitors; (b) I-V characteristics of the capacitors with different $\mathrm{ZrO}_{2}$ film thicknesses with and without the surface treatment; (c) $\mathrm{C}-\mathrm{V}$ characteristics of the capacitors at different frequencies between $10 \mathrm{kHz}$ and $1 \mathrm{MHz}$; (d) C-F characteristics of the capacitors between $1 \mathrm{kHz}$ and $10 \mathrm{MHz}$.

In order for them to be used in flexible capacitors, the flexibility properties of the graphene electrodes need to be investigated. Figure 4a shows the schematic diagram of the ultrathin, transparent and flexible capacitors fabricated directly on PEN substrate. Figure $4 \mathrm{~b}$ shows the transmittance spectra of the capacitors in the wavelength range from 400 to $800 \mathrm{~nm}$. The capacitors exhibited an average optical transmittance of close to $70 \%$. The loss of transmittance originated mostly from the PEN substrates, as seen in Figure $4 \mathrm{~b}$. The inset in Figure $4 \mathrm{~b}$ shows that the graphene had an average transmittance of over $90 \%$, and the capacitors on quartz substrates exhibited a transmittance of over $80 \%$ throughout the whole visible range. The English characters "TFS" can be clearly seen through the transparent capacitor, as shown in the inset of Figure $4 \mathrm{~b}$. Therefore, the intrinsic transmittance of our flexible nano-capacitors is valuable for applications in transparent electronics. 


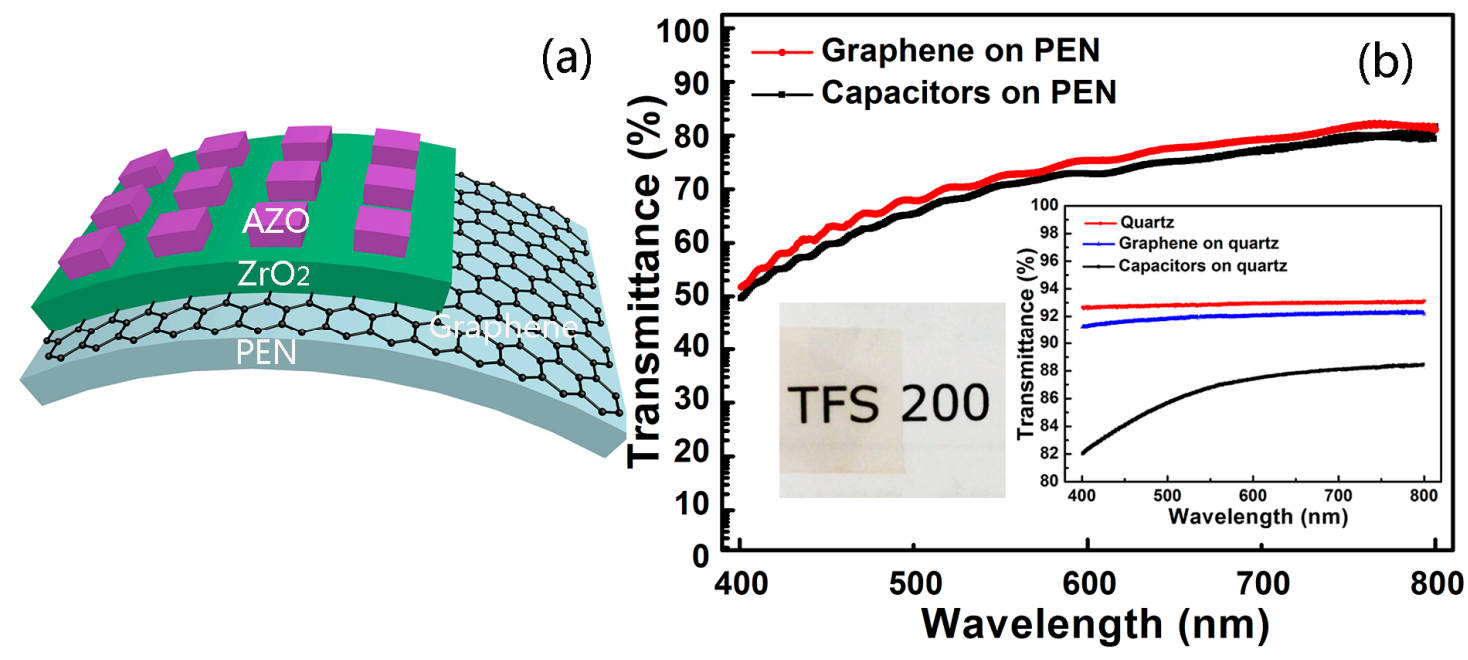

Figure 4. (a) The schematic diagram of the ultrathin, transparent and flexible capacitors; (b) The optical transmittance spectra of the capacitors on PEN substrates. The inset shows the optical photograph of the actual capacitor device with the characters "TFS 200" in the background, and the optical transmittance spectra of graphene and capacitors on quartz substrates.

The flexibility and anti-fatigue properties of the graphene and $150 \mathrm{~nm}$ thick AZO electrodes on PEN were studied by bending tests in convex condition. The variation in sheet resistance is expressed as $\left(R-R_{0}\right) / R_{0}$, where $R_{0}$ and $R$ represent the sheet resistance before and after bending, respectively. Figure 5a shows that the sheet resistance of the graphene electrodes stayed nearly invariant when the bending radius was decreased from 40 to $4.5 \mathrm{~mm}$, but increased apparently below $3 \mathrm{~mm}$. Meanwhile, the sheet resistance of the AZO electrodes remained almost unchanged in a bending radius range from 40 to $10 \mathrm{~mm}$, as shown in Figure 5b. The anti-fatigue properties of the graphene and AZO electrodes were tested at bending radii of 4.5 and $10 \mathrm{~mm}$, and the data are shown in Figure $5 \mathrm{c}, \mathrm{d}$, respectively. The sheet resistance of the graphene electrodes increased slightly with lower numbers of bending times $(\leq 400)$, and rose significantly above 400 times at a radius of $4.5 \mathrm{~mm}$. In contrast, the electrical properties of the AZO electrodes deteriorated seriously. Fortunately, the sheet resistance of graphene and AZO electrodes remained almost unchanged below 800 bending times, and increased only a little when it reached 1000 times at a radius of $10 \mathrm{~mm}$. As a consequence, the graphene and AZO electrodes show excellent flexibility and relatively good anti-fatigue properties at larger bending radius $(\geq 10 \mathrm{~mm})$. It should be pointed out that the graphene electrodes were easily damaged, and their resistance increased significantly during the bending process in the concave condition, which deteriorated the flexibility of the capacitors. Therefore, bending tests are crucial for those capacitors that use graphene and AZO as the electrodes.

For the capacitors on PEN substrates without bending, the electrical characteristics remained almost the same as those on quartz substrates. Figure 6a shows the image of the capacitors in bending conditions. In Figure $6 b$, the leakage current of the flexible capacitors did not change markedly after bending in a radius range larger than $10 \mathrm{~mm}$ when the voltage was swept between -2 and $2 \mathrm{~V}$, but differed greatly at a bending radius of $4.5 \mathrm{~mm}$. The leakage current increased from $3.3 \times 10^{-6}$ to $7.9 \times 10^{-4}\left(\mathrm{~A} / \mathrm{cm}^{2}\right)$ at $1 \mathrm{~V}$ when the number of bending times fell into the range between 0 and 600 times, and increased greatly to $6.8 \times 10^{-2}\left(\mathrm{~A} / \mathrm{cm}^{2}\right)$ at around 800 times and even $0.6\left(\mathrm{~A} / \mathrm{cm}^{2}\right)$ at around 1000 times at a radius of $10 \mathrm{~mm}$, as shown in Figure 6c. In Figure 6d, the capacitance of the capacitors remained almost invariant at a bending radius of $10 \mathrm{~mm}$, but dropped slightly at a bending radius of $4.5 \mathrm{~mm}$, relative to that without bending in a frequency range between $1 \mathrm{kHz}$ and $1 \mathrm{MHz}$. Therefore, the flexible capacitors are able to work in harsh bending conditions even at a radius of $4.5 \mathrm{~mm}$. Of course, the larger the bending radius, the better the anti-fatigue properties. These results were superior to what we have reported before [32]. 

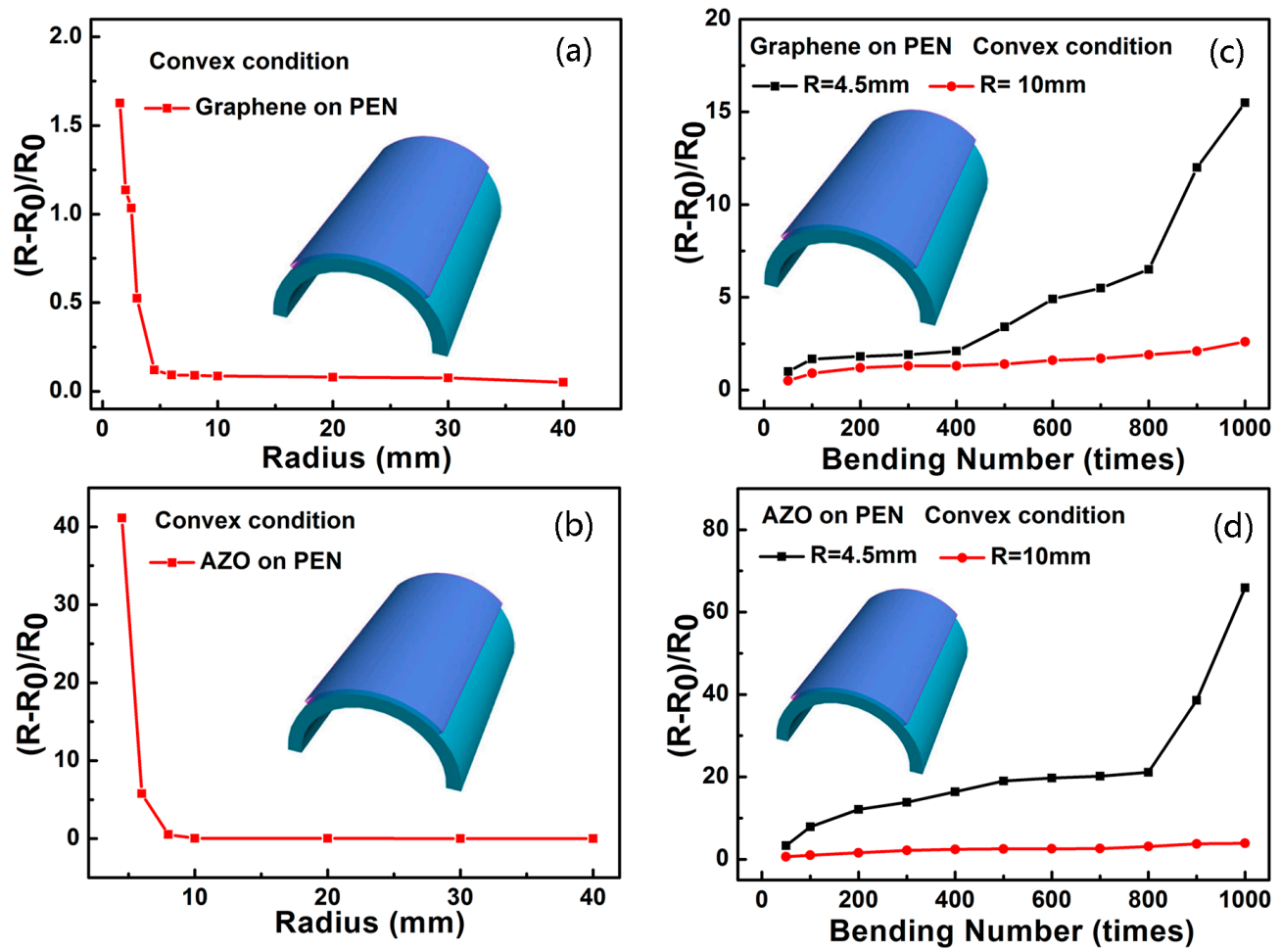

Figure 5. Variation of sheet resistance of (a) graphene and (b) AZO in convex conditions with different bending radii. Variation of sheet resistance of (c) graphene and (d) AZO in convex conditions with different bending numbers at a radius of 4.5 and $10 \mathrm{~mm}$, respectively.
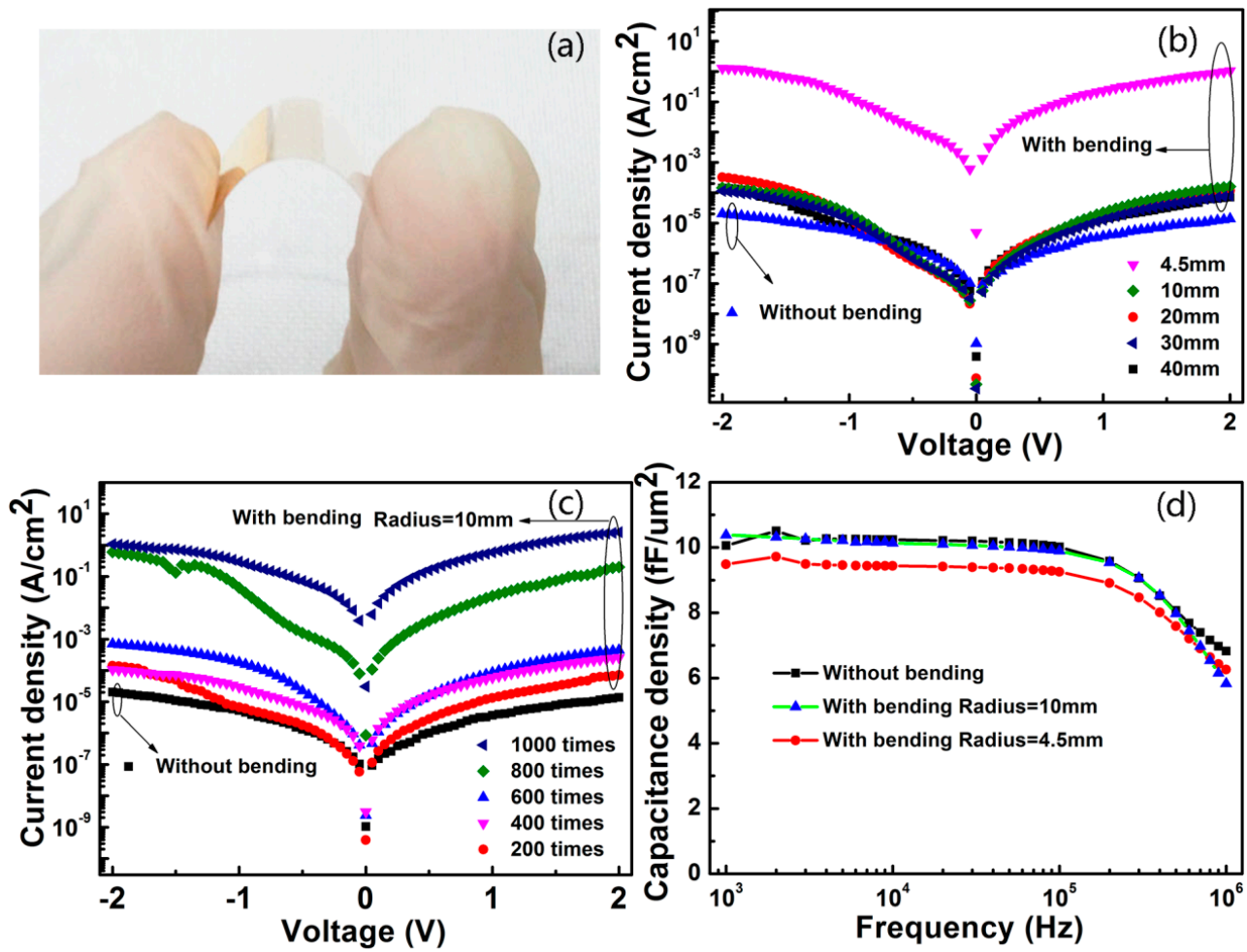

Figure 6. (a) The image of the capacitors on PEN; electrical characteristics of the capacitors in bending conditions; (b) I-V curves at different bending radii; (c) I-V curves with different bending times at a radius of $10 \mathrm{~mm}$; (d) C-F curves with and without bending. 
The surface morphologies of the devices were studied by AFM measurements to understand why the leakage current increased significantly and the capacitance density dropped slightly after the bending tests. The surface morphologies of the $\mathrm{ZrO}_{2}$ dielectric layers after bending and cyclic bending are shown in Figure 7a-c. No obvious flaws appeared in the $\mathrm{ZrO}_{2}$ dielectric layer after bending at a radius of $10 \mathrm{~mm}$, as seen in Figure 7a. However, after cyclic bending for 1000 times, as can be seen from Figure $7 \mathrm{~b}$, fissures and bulges were apparent. Figure $7 \mathrm{c}$ shows the magnified fissures that provide a transport channel for current between the graphene and AZO electrodes. There is no doubt that the transport channel would be increasingly unobstructed for the current with an increase in the bending number, which results in a substantial increase in the leakage current. The capacitance is expressed as $C=\left(\varepsilon_{0} \varepsilon_{\mathrm{r}} \mathrm{s}_{\mathrm{v}}\right) / \mathrm{d}$, where $C$ represents the capacitance density, and $\varepsilon_{0}, \varepsilon_{\mathrm{r}}, \mathrm{s}_{\mathrm{V}}$, and d represent the vacuum dielectric constant, the relative dielectric constant, the longitudinal area of the polar plate, and the thickness of dielectric layer, respectively. The $\mathrm{s}_{\mathrm{v}}$ might decrease and the $\mathrm{d}$ increase due to the appearance of the fissures and bulges in the $\mathrm{ZrO}_{2}$ dielectric layer after the bending tests. Meanwhile, $\varepsilon_{0}$ and $\varepsilon_{\mathrm{r}}$ remain unchanged. Hence, the capacitance density slightly drops after the bending tests. The fissures and bulges did not exist in the AZO electrodes after bending and cyclic bending 1000 times, as shown in Figure 7d,e, respectively. The details of the surface morphologies can be seen more clearly in the magnified image, which are presented in Figure 7f. The small tapered crystals of AZO films can be observed, and the film surface is smooth and continuous. This can be accounted for by the smaller sizes of the AZO pads $\left(100 \times 100 \mu \mathrm{m}^{2}\right)$ in comparison to the bending radius $(10 \mathrm{~mm})$. Therefore, the AZO electrodes sustained almost no damage in the bending process.
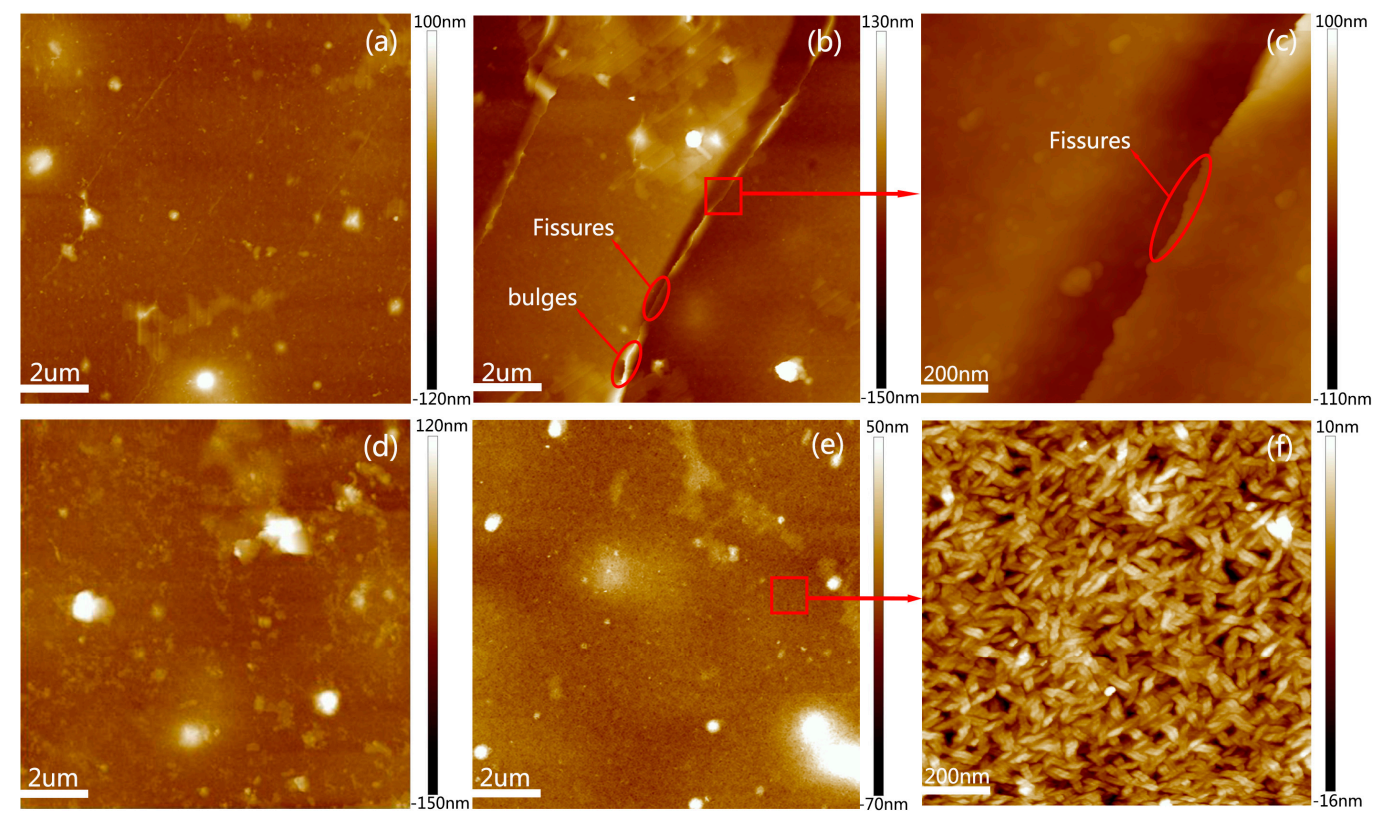

Figure 7. The AFM images of the devices after bending and cyclic bending 1000 times at a radius of $10 \mathrm{~mm}$. The surface of $\mathrm{ZrO}_{2}$ dielectric layers (a) without and (b) with cyclic bending; (c) magnified image. The surface of AZO electrodes (d) without and (e) with cyclic bending; (f) magnified image.

To understand how the leakage current of the flexible capacitors is generated, models of Ohmic conduction, space-charge-limited-current (SCLC) and Schottky emission were used. Generally, Schottky emission and Ohmic conduction play an important role in the mechanism of the leakage current at low fields. Figure 8a shows the relationship between $\ln (\mathrm{J})$ and $\ln (\mathrm{E})$. Here, the J and $\mathrm{E}$ represent the leakage current density and the electric field, respectively. The slope was close to 1 when the field was below $0.2 \mathrm{MV} / \mathrm{cm}$, which demonstrated that Ohmic conduction existed. Such a behavior disappeared when the field was above $0.2 \mathrm{MV} / \mathrm{cm}$. The slope was about 2 at higher 
fields ( $\mathrm{E}>0.8 \mathrm{MV} / \mathrm{cm}$ ), which satisfied the SCLC model. In Figure $8 \mathrm{~b}$, a linear relationship was observed for the Schottky emission, with $\ln (J)$ proportional to $E^{1 / 2}$. As the fitted relative dielectric constant (8.2) approached the measured one (11.6), the Schottky emission dominated at low fields $(0.2<\mathrm{E}<0.7 \mathrm{MV} / \mathrm{cm})$. However, the fitted relative dielectric constant reached 19.3 at high fields $(\mathrm{E}>1 \mathrm{MV} / \mathrm{cm})$, which differed greatly from the measured one (11.6). Thus, the Schottky emission could be excluded at high fields. It can be concluded that Ohmic conduction dominates when the field is lower than $0.2 \mathrm{MV} / \mathrm{cm}$, while the Schottky emission plays the main role when $0.2<\mathrm{E}<0.7 \mathrm{MV} / \mathrm{cm}$, and the SCLC mechanism is suitable when $\mathrm{E}>0.8 \mathrm{MV} / \mathrm{cm}$.
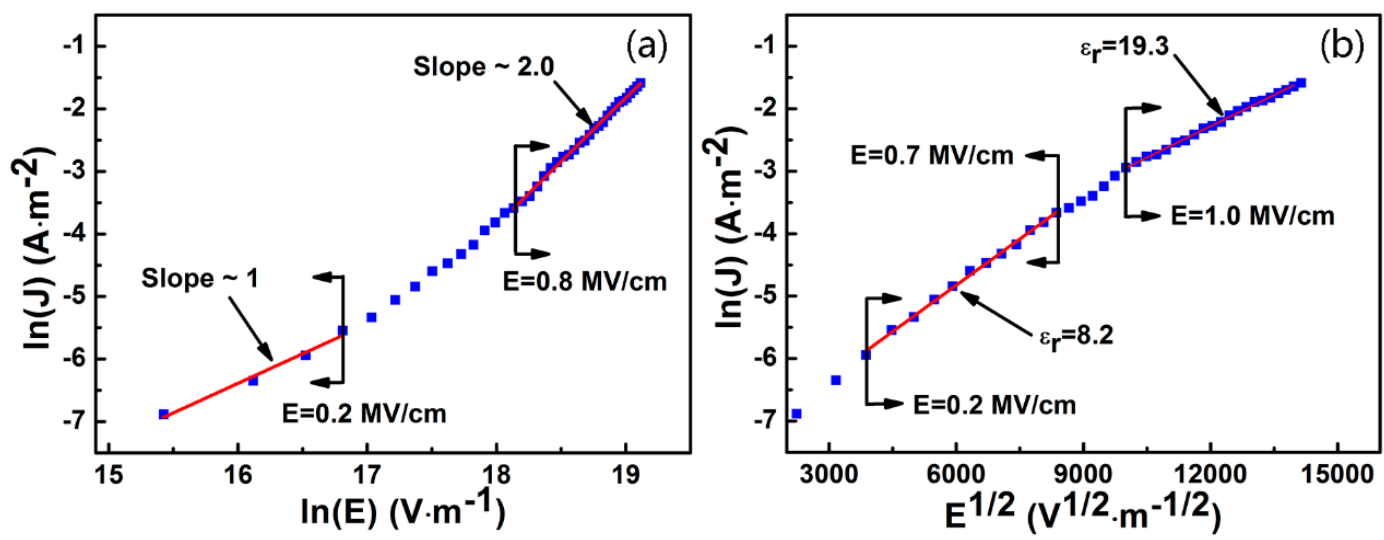

Figure 8. The leakage current mechanism: (a) Ohmic plots, space-charge-limited-current (SCLC) plots and (b) Schottky plots.

\section{Experimental Section}

\subsection{Device Fabrication Methods}

Before device fabrication, PEN and quartz substrates were ultrasonically cleaned in acetone for $10 \mathrm{~min}$, followed by heating in alcohol at $60^{\circ} \mathrm{C}$ for $10 \mathrm{~min}$ and in deionized water for $10 \mathrm{~min}$, and then the cleaned substrates were purged by high-pressure $\mathrm{N}_{2}$ to remove the remaining water and other particles from the surfaces. Commercial single-layer graphene (SG) was grown by CVD on copper foil (2D Carbon Tech Inc. LTD, Changzhou, China). SG was then transferred onto the PEN and quartz substrates from $\mathrm{Cu}$ foil by using the roll-to-roll method [8]. Subsequently, the substrates with graphene were rapidly transferred to the ALD (TFS-200, Beneq, Vantaa, Helsinki, Finland) chamber and $\mathrm{H}_{2} \mathrm{O}$ molecules were distributed uniformly on the graphene by gas-solid physical absorption at $100{ }^{\circ} \mathrm{C}$. Thereafter, $5 \mathrm{~nm}$ thick $\mathrm{ZrO}_{2}$ films were deposited on the graphene at $100{ }^{\circ} \mathrm{C}$ as seed layers. Then, thicker $\mathrm{ZrO}_{2}$ dielectric films with varying thicknesses were deposited on the $\mathrm{ZrO}_{2}$ seed layers at $150{ }^{\circ} \mathrm{C}$. Finally, $150 \mathrm{~nm}$ thick AZO films were deposited in situ on the $\mathrm{ZrO}_{2}$ dielectric films at $150{ }^{\circ} \mathrm{C}$ as the top electrodes. Photolithography and wet etching processes were carried out to define the as-prepared top AZO films into isolated pads. The final AZO pads were about $100 \times 100 \mu \mathrm{m}^{2}$ in area, and the distance between two pads was about $400 \mu \mathrm{m}$.

\subsection{Growth Conditions}

Tetrakisdimethylamino zirconium (TDMAZ) and $\mathrm{H}_{2} \mathrm{O}$ were used to grow $\mathrm{ZrO}_{2}$ at 100 and $150{ }^{\circ} \mathrm{C}$. The growth rate was about $0.2 \mathrm{~nm} /$ cycle at $100{ }^{\circ} \mathrm{C}$ and $0.1 \mathrm{~nm} /$ cycle at $150{ }^{\circ} \mathrm{C}$, respectively. Diethyl zinc (DEZn), trimethyl aluminum (TMA) and $\mathrm{H}_{2} \mathrm{O}$ were used to deposit the $\mathrm{AZO}$ films, and the growth rate was approximately $4 \mathrm{~nm}$ per period. Each period consisted of 20 cycles of $\mathrm{ZnO}$ and 1 cycle of $\mathrm{Al}_{2} \mathrm{O}_{3}$. The growth rates of $\mathrm{ZnO}$ and $\mathrm{Al}_{2} \mathrm{O}_{3}$ at $150^{\circ} \mathrm{C}$ were 0.2 and $0.1 \mathrm{~nm} /$ cycle, respectively. 


\subsection{Characterization Methods}

The surface morphology of the $\mathrm{ZrO}_{2}$ films was measured by atomic force microscope (AFM, Bruker Multimode 8, Karisruhe, Germany). Raman spectroscopy (Raman, HORIBA Jobin Yvon LabRam, Paris, France) was implemented to determine whether the treatment of the graphene surface is suitable for the ALD process. The sheet resistance of the graphene and AZO electrodes was measured by hall measurements (Model 7707A, Lake Shore, WA, USA). Capacitance versus frequency (C-F), capacitance versus voltage $(\mathrm{C}-\mathrm{V})$, and leakage current versus voltage (I-V) were measured with a Keithley 4200 semiconductor analyzer (Keithley, Johnston, OH, USA). The optical transmittance was measured by a UV-VIS-NIR spectrophotometer (Varian Cary 5000, Vraian, CA, USA).

\section{Conclusions}

In summary, we have successfully fabricated ultrathin, transparent and flexible capacitors on low-cost and flexible PEN substrates by ALD. $\mathrm{H}_{2} \mathrm{O}$ adsorption is necessary to make graphene electrodes on which high-quality $\mathrm{ZrO}_{2}$ dielectric films can be deposited. The capacitors show a relatively large capacitance of $10.3 \mathrm{fF} / \mu \mathrm{m}^{2}$ at $10 \mathrm{kHz}$ with a low leakage current of $5.3 \times 10^{-6} \mathrm{~A} / \mathrm{cm}^{2}$ at $1 \mathrm{~V}$, and can work at a bending radius of $10 \mathrm{~mm}$ without any deterioration of electrical performance in convex conditions. Ohmic conduction predominates when the field is lower than $0.2 \mathrm{MV} / \mathrm{cm}$, while Schottky emission plays the main role when $0.2<\mathrm{E}<0.7 \mathrm{MV} / \mathrm{cm}$, and the SCLC mechanism is suitable when $\mathrm{E}>0.8 \mathrm{MV} / \mathrm{cm}$. The capacitors present an average optical transmittance of close to $70 \%$ in the visible range, opening possibilities for application in transparent and flexible integrated circuits.

Acknowledgments: This work was supported by the National Key Research and Development Plan (MOST) under Grant Number 2017YFA0205802, the NSFC under Grant Number 11574235 and the funding of Jiangsu Province No BK20151250.

Author Contributions: Tao Guo performed the experiments and wrote the manuscript. Hao Wu conceived the study and participated in its design. Xi Su and Heng Zhang participated in the design of the experiments. Guozhen Zhang analyzed the data. Jiaxian Wan and Xue Chen participated in the measurements. Chang Liu supervised the overall study. All authors read and approved the final manuscript.

Conflicts of Interest: The authors declare no conflict of interest.

\section{References}

1. Ju, S.; Facchetti, A.; Xuan, Y.; Liu, J.; Ishikawa, F.; Ye, P.; Zhou, C.; Marks, T.J.; Janes, D.B. Fabrication of fully transparent nanowire transistors for transparent and flexible electronics. Nat. Nanotechnol. 2007, 2, 378-384. [CrossRef] [PubMed]

2. Sekitani, T.; Zschieschang, U.; Klauk, H.; Someya, T. Flexible organic transistors and circuits with extreme bending stability. Nat. Mater. 2010, 9, 1015-1022. [CrossRef] [PubMed]

3. Liu, P.-T.; Chu, L.-W. Innovative voltage driving pixel circuit using organic thin-film transistor for amoleds. J. Displ. Technol. 2009, 5, 224-228. [CrossRef]

4. Chen, B.-T.; Tai, Y.-H.; Kuo, Y.-J.; Tsai, C.-C.; Cheng, H.-C. New pixel circuits for driving active matrix organic light emitting diodes. Solid-State Electron. 2006, 50, 272-275. [CrossRef]

5. Yoo, Y.W.; Jeon, W.; Lee, W.; An, C.H.; Kim, S.K.; Hwang, C.S. Structure and electrical properties of Al-doped $\mathrm{HfO}_{2}$ and $\mathrm{ZrO}_{2}$ films grown via atomic layer deposition on mo electrodes. ACS Appl. Mater. Interfaces 2014, 6, 22474-22482. [CrossRef] [PubMed]

6. Pang, S.; Hernandez, Y.; Feng, X.; Mullen, K. Graphene as transparent electrode material for organic electronics. Adv. Mater. 2011, 23, 2779-2795. [CrossRef] [PubMed]

7. Xuan, W.; Linjie, Z.; Klaus, M. Transparent, conductive graphene electrodes for dye-sensitized solar cells. Nano Lett. 2008, 8, 323-327.

8. Bae, S.; Kim, H.; Lee, Y.; Xu, X.; Park, J.S.; Zheng, Y.; Balakrishnan, J.; Lei, T.; Kim, H.R.; Song, Y.I.; et al. Roll-to-roll production of 30-inch graphene films for transparent electrodes. Nat. Nanotechnol. 2010, 5, 574-578. [CrossRef] [PubMed] 
9. Wu, J.; Becerril, H.A.; Bao, Z.; Liu, Z.; Chen, Y.; Peumans, P. Organic solar cells with solution-processed graphene transparent electrodes. Appl. Phys. Lett. 2008, 92, 263302. [CrossRef]

10. Zhang, L.; Jiang, H.C.; Liu, C.; Dong, J.W.; Chow, P. Annealing of $\mathrm{Al}_{2} \mathrm{O}_{3}$ thin films prepared by atomic layer deposition. J. Phys. D Appl. Phys. 2007, 40,3707-3713. [CrossRef]

11. Zhang, G.Z.; Wu, H.; Chen, C.; Wang, T.; Wang, P.Y.; Mai, L.Q.; Yue, J.; Liu, C. Transparent capacitors based on nanolaminate $\mathrm{Al}_{2} \mathrm{O}_{3} / \mathrm{TiO}_{2} / \mathrm{Al}_{2} \mathrm{O}_{3}$ with $\mathrm{H}_{2} \mathrm{O}$ and $\mathrm{O}_{3}$ as oxidizers. Appl. Phys. Lett. 2014, 104, 163503. [CrossRef]

12. Carcia, P.F.; McLean, R.S.; Reilly, M.H. High-performance zno thin-film transistors on gate dielectrics grown by atomic layer deposition. Appl. Phys. Lett. 2006, 88, 123509. [CrossRef]

13. Wu, Y.-H.; Kao, C.-K.; Chen, B.-Y.; Lin, Y.-S.; Li, M.-Y.; Wu, H.-C. High density metal-insulator-metal capacitor based on $\mathrm{ZrO}_{2} / \mathrm{Al}_{2} \mathrm{O}_{3} / \mathrm{ZrO}_{2}$ laminate dielectric. Appl. Phys. Lett. 2008, 93, 033511. [CrossRef]

14. Ye, G.; Wang, H.; Arulkumaran, S.; Ng, G.I.; Li, Y.; Liu, Z.H.; Ang, K.S. Band alignment between gan and $\mathrm{ZrO}_{2}$ formed by atomic layer deposition. Appl. Phys. Lett. 2014, 105, 022106. [CrossRef]

15. Fakhri, M.; Theisen, M.; Behrendt, A.; Görrn, P.; Riedl, T. Top-gate zinc tin oxide thin-film transistors with high bias and environmental stress stability. Appl. Phys. Lett. 2014, 104, 251603. [CrossRef]

16. Zhang, G.; Wu, H.; Wang, X.; Zhang, D.; Wang, T.; Liu, C. Modulation of the dissipation factor in transparent $\mathrm{AlZnO} / \mathrm{ZrO}_{2} / \mathrm{AlZnO}$ capacitors. J. Alloys Compd. 2017, 690, 777-782. [CrossRef]

17. Lee, B.; Park, S.-Y.; Kim, H.-C.; Cho, K.; Vogel, E.M.; Kim, M.J.; Wallace, R.M.; Kim, J. Conformal $\mathrm{Al}_{2} \mathrm{O}_{3}$ dielectric layer deposited by atomic layer deposition for graphene-based nanoelectronics. Appl. Phys. Lett. 2008, 92, 203102. [CrossRef]

18. Jeong, S.J.; Gu, Y.; Heo, J.; Yang, J.; Lee, C.S.; Lee, M.H.; Lee, Y.; Kim, H.; Park, S.; Hwang, S. Thickness scaling of atomic-layer-deposited $\mathrm{HfO}_{2}$ films and their application to wafer-scale graphene tunnelling transistors. Sci. Rep. 2016, 6, 20907. [CrossRef] [PubMed]

19. George, S.M. Atomic layer deposition: An overview. Chem. Rev. 2010, 110, 111-131. [CrossRef] [PubMed]

20. Alles, H.; Aarik, J.; Aidla, A.; Fay, A.; Kozlova, J.; Niilisk, A.; Pärs, M.; Rähn, M.; Wiesner, M.; Hakonen, P.; et al. Atomic layer deposition of $\mathrm{HfO}_{2}$ on graphene from $\mathrm{HfCl}_{4}$ and $\mathrm{H}_{2} \mathrm{O}$. Open Phys. 2011, 9. [CrossRef]

21. Fisichella, G.; Schiliro, E.; Di Franco, S.; Fiorenza, P.; Lo Nigro, R.; Roccaforte, F.; Ravesi, S.; Giannazzo, F. Interface electrical properties of $\mathrm{Al}_{2} \mathrm{O}_{3}$ thin films on graphene obtained by atomic layer deposition with an in situ seedlike layer. ACS Appl. Mater. Interfaces 2017, 9, 7761-7771. [CrossRef] [PubMed]

22. Fallahazad, B.; Lee, K.; Lian, G.; Kim, S.; Corbet, C.M.; Ferrer, D.A.; Colombo, L.; Tutuc, E. Scaling of $\mathrm{Al}_{2} \mathrm{O}_{3}$ dielectric for graphene field-effect transistors. Appl. Phys. Lett. 2012, 100, 093112. [CrossRef]

23. McDonnell, S.; Azcatl, A.; Mordi, G.; Floresca, C.; Pirkle, A.; Colombo, L.; Kim, J.; Kim, M.; Wallace, R.M. Scaling of $\mathrm{HfO}_{2}$ dielectric on cvd graphene. Appl. Surf. Sci. 2014, 294, 95-99. [CrossRef]

24. Tiginyanu, I.M.; Junige, M.; Oddoy, T.; Yakimova, R.; Darakchieva, V.; Wenger, C.; Lupina, G.; Kitzmann, J.; Albert, M.; Bartha, J.W. Atomic layer deposition of $\mathrm{Al}_{2} \mathrm{O}_{3}$ on $\mathrm{NF}_{3}$-pre-treated graphene. Proc. SPIE 2015, 9519, 951915.

25. Shin, W.C.; Bong, J.H.; Choi, S.Y.; Cho, B.J. Functionalized graphene as an ultrathin seed layer for the atomic layer deposition of conformal high-k dielectrics on graphene. ACS Appl. Mater. Interfaces 2013, 5, 11515-11519. [CrossRef] [PubMed]

26. Kim, S.; Nah, J.; Jo, I.; Shahrjerdi, D.; Colombo, L.; Yao, Z.; Tutuc, E.; Banerjee, S.K. Realization of a high mobility dual-gated graphene field-effect transistor with $\mathrm{Al}_{2} \mathrm{O}_{3}$ dielectric. Appl. Phys. Lett. 2009, 94, 062107. [CrossRef]

27. Zheng, L.; Cheng, X.; Cao, D.; Wang, G.; Wang, Z.; Xu, D.; Xia, C.; Shen, L.; Yu, Y.; Shen, D. Improvement of $\mathrm{Al}_{2} \mathrm{O}_{3}$ films on graphene grown by atomic layer deposition with pre- $\mathrm{H}_{2} \mathrm{O}$ treatment. ACS Appl. Mater. Interfaces 2014, 6, 7014-7019. [CrossRef] [PubMed]

28. Deshpande, A.; LeRoy, B.J. Scanning probe microscopy of graphene. Phys. E Low-Dimens. Syst. Nanostruct. 2012, 44, 743-759. [CrossRef]

29. Park, Y.H.; Kim, M.H.; Kim, S.B.; Jung, H.J.; Chae, K.; Ahn, Y.H.; Park, J.-Y.; Rotermund, F.; Lee, S.W. Enhanced nucleation of high-k dielectrics on graphene by atomic layer deposition. Chem. Mater. 2016, 28, 7268-7275. [CrossRef]

30. Yamada, Y.; Murota, K.; Fujita, R.; Kim, J.; Watanabe, A.; Nakamura, M.; Sato, S.; Hata, K.; Ercius, P.; Ciston, J.; et al. Subnanometer vacancy defects introduced on graphene by oxygen gas. J. Am. Chem. Soc. 2014, 136, 2232-2235. [CrossRef] [PubMed] 
31. Ferrari, A.C.; Meyer, J.C.; Scardaci, V.; Casiraghi, C.; Lazzeri, M.; Mauri, F.; Piscanec, S.; Jiang, D.; Novoselov, K.S.; Roth, S.; et al. Raman spectrum of graphene and graphene layers. Phys. Rev. Lett. 2006, 97, 187401. [CrossRef] [PubMed]

32. Zhang, G.; Wu, H.; Wang, X.; Wang, T.; Liu, C. Transparent capacitors with hybrid ZnO:Al and Ag nanowires as electrodes. Nanotechnology 2016, 27, 105204. [CrossRef] [PubMed] 